\title{
Seismic Performances of Mountainous Continuous Rigid Frame Solid and Hollow Pier Railway Bridges
}

\author{
Akhil Subedi*, Gopal S. Bhandari, Paribesh Parajuli \\ Department of Bridge and Tunnel Engineering, School of Civil Engineering, Southwest Jiaotong University, Chengdu, China \\ Email: ^subedi.akhil@outlook.com, gopalbhandari@outlook.com, pariverse@gmail.com
}

How to cite this paper: Subedi, A., Bhandari, G.S. and Parajuli, P. (2018) Seismic Performances of Mountainous Continuous Rigid Frame Solid and Hollow Pier Railway Bridges. Open Journal of Civil Engineering, 8, 489-507.

https://doi.org/10.4236/ojce.2018.84035

Received: September 16, 2018

Accepted: December 10, 2018

Published: December 13, 2018

Copyright ( 92018 by authors and Scientific Research Publishing Inc. This work is licensed under the Creative Commons Attribution International License (CC BY 4.0).

http://creativecommons.org/licenses/by/4.0/

\begin{abstract}
This paper focuses on the seismic performance of mountainous railway bridges having different pier type i.e. rectangular hollow piers and solid piers. The piers used were of same materials and inertial properties. For this, 3-D FEM models of these bridges were created by ANSYS 15.0. For seismic assessment, Response Spectrum and Dynamic Time-History Analysis methods were adopted. Different types of earthquake waves used were Elcentro, Wenchuan and Nepal earthquakes, all normalized to $0.3 \mathrm{~g}$ Peak Ground Acceleration (PGA). The study concluded that even though the hollow pier bridges are susceptible to large displacements, its dealing with internal forces is remarkable compared to solid pier bridges.
\end{abstract}

\section{Keywords}

Hollow Pier Mountainous Bridge, Solid Pier Mountainous Bridge, Response Spectrum Analysis, Modal Analysis, Time-History Analysis

\section{Introduction}

Earthquake follows hazard for many bridges which has turned out to be fatal in some cases. Although people are influenced for large number of years from seismic activities, concrete research on bridges started not long ago. Bridges should be designed such that only non-hazardous, and minor damage occurs which allows to maintain safety measures after an earthquake. Pier failure from seismic hazard has been one of the most likely failures but a well-designed and strong seismic performance of the bridge can greatly reduce the hazard. In general, under seismic loads, in long span continuous mountainous bridge, the stiffness of the pier becomes obviously less because it is long and slender; there- 
fore, it requires seismic performance reviews [1]. As pier height increases displacement value of pier increases. An investigation about highway and railway bridges in China showed that the heights of the piers of about $40 \%$ bridges are more than 40 meters high [2]. In this paper, seismic performance of mountainous bridges with typical high hollow and solid piers, and large span were analyzed. We tried to show hollow pier bridges accommodate high shear, axial and moment demands which maximize structural efficiency and cutting-off the large mass of the piers to seismic response.

The experimental evidences studied in these types of topics are very few, whereas the seismic study of reinforced concrete continuous mountainous bridge having different pier systems is unique. The seismic analyses performed for bridges so far were shear resistance and strengthening of solid pier bridges, therefore those results cannot be directly applied to hollow pier bridges. Mo and Nien [3] and Pinto et al. [4] investigated the seismic performances and attributes of similar hollow high strength concrete bridge piers. Ou et al. [5] used a $3 \mathrm{D}$ FEM of hollow precast post-tensioned reinforced concrete segmented piers and a cyclic loading pattern was applied to the model.

\subsection{Equations of Motion}

The dynamic behavior of structures involves motion of several masses in shapes that are not known before the analysis. Thus, the theory of dynamics of a single degree of freedom (SDOF) must be adopted to deal with several masses and systems with distributed mass like beam and frame structures such as bridges. The first extension of the theory is from SDOF involving a single mass which is to be extended to multiple degrees of freedom, describing the coupled motion of several concentrated masses systems. This theory is called modal analysis and includes terms such as mode shapes, modal mass and modal stiffness.

The dynamic responses of a linear system with $n$ degrees of freedom, $u(t) T=\left[u_{1}(t), u_{2}(t), \cdots, u_{n}(t)\right]$ to ground motions is described by the set of second order differential equations [6]

$$
m \ddot{u}+c \dot{u}+k u=-m I \ddot{u}_{g}
$$

The physical parameters of MDOF based on Equation (1) are: the mass matrix $m$, the viscous damping matrix $c$ and the stiffness matrix $k$. Effective earthquake forces are represented by $m I \ddot{u}_{g}$, where $I$ is the influence vector representing the displacements of the masses resulting from static application of a unit ground displacement. Mode shapes and periods are found by solving the generalized eigenvalue problem which is

$$
\left(k-\omega^{2} m\right) \varphi=0
$$

The complete solution to the generalized eigenvalue problem consists of $n$ sets of eigenvalues and eigenvectors, arranged as corresponding pairs of natural frequency $\omega_{j}$ and mode shape vector $\varphi_{j}$. 


$$
\omega_{j}, \varphi_{j} \quad j=1,2,3, \cdots, n
$$

Modal mass and modal stiffness corresponding to mode $j$ are defined as

$$
\begin{aligned}
& m_{j}=\varphi_{j}^{\mathrm{T}} m \varphi_{j} \\
& k_{j}=\varphi_{j}^{\mathrm{T}} k \varphi_{j}
\end{aligned}
$$

The Eigen frequency, $\omega_{j}$ can be expressed by the ratio of modal stiffness to modal mass by pre-multiplication of the generalized eigenvalue equation with $\varphi_{j}^{T}$. This relation is called Rayleigh's quotient and generalizes the definition of the angular frequency for a SDOF system [7].

\subsection{Structural Seismic Analysis Methods}

Seismic force theory is study of the dynamic effects of seismic ground motion which are generated on structures. Seismic responses of structures depend on the dynamic characteristics of vibration and structure or profile of the soil on which the structure is lying. The most important earthquake ground motion characteristics or parameters of structures are: the duration, the amplitude of the displacement-velocity-accelerations, and frequency of the ground motions. A ground motion at the structure's place is basically a combination or superposition of many complex different vibrational frequencies. The structure should be analyzed to avoid resonance. Currently, the bridge seismic response analysis method based on consideration of the characteristics of ground motions is categorized into two types 1) Deterministic seismic response analysis; and 2) Non-deterministic (probabilistic) seismic response analysis.

Deterministic methods focus on a single earthquake which ensures that the event is realistic, i.e. it has some probability of occurrence. Deterministic method is the seismic force loads on the structure as already determined, for solving this structural dynamic load response. Non-deterministic method is actually based on random vibration theory. The ground motions are considered as a random process, in which statistical parameters are used to get structural dynamic response. The world bridge seismic design specifications commonly use deterministic seismic response analysis methods. In deterministic seismic response analysis methods, there are three methods which are static method, response spectrum method and dynamic time-history analysis [8].

\subsubsection{Modal Response Spectrum Analysis}

Modal Response Spectrum Analysis in structural mechanics is adopted to determine the natural mode shapes and natural frequencies of an object or a structure during the free vibration. The physical representation of the eigenvalues and eigenvectors is found from solving the Eigen system of a structure; they represent the frequencies and corresponding mode shapes respectively. Sometimes, it is found that the only modes we want to find out are of the lowest frequencies because they can be the most prominent modes at which the object will vibrate that may eclipse all the modes of higher frequency. If the natural fre- 
quency of the structure matches an earthquake's frequency, the structure may experience structural damage due to resonance effect. So, it is desirable to design a structure such that natural frequency of the structure and earthquake doesn't match.

The multiple degree-of-freedom (MDOF) structural system matrices, forces, and displacements can be changed into single degree-of-freedom (SDOF) modal solution, forces $\left(P_{i}\right)$, and displacements $\left(q_{i}\right)$ for each mode [9]. For each SDOF system of value $T$, the dynamic response is computed using numerical procedures. The value assigned to each of the dynamic response terms for the system is the peak response value computed during earthquake shaking. The maximum responses contributed by each mode of vibration is determined by using relationships that correlate loading to peak response as a function of modal frequency (or period). This response spectra are graphs of the maximum values of acceleration, velocity, and/or displacement response of thousands series of damped elastic SDOF systems confronted to an acceleration time history.

Several methods have been adopted to merge the modal responses to find out the highest or peak value of the total response. It is not correct just to add up the modal responses because they attain their peaks at different time instants, and the combined response attains its peak at different time instants too. At present, the application of more random vibration theory based on various methods is proposed, such as complete quadratic combination method (CQC) and the square and Kaiping method (SRSS). CQC is relatively a new technique of modal combination method [10]. For modal combination, complete quadratic combination (CQC) method has been considered in this study paper.

\subsubsection{Time-History Analysis}

A time-history is a description of ground acceleration or related quantities such as velocity and displacement as a function of time, assuming all members remain elastic and no displacement limit is reached beyond. There are situations where the simulation of structural response using an elastic response spectrum is not considered genuinely appropriate, and a full dynamic analysis is required. These situations may include bridges designed for a high degree of ductility, highly irregular structures, structures for which higher modes are likely to be excited and some of the critical structures. By using nonlinear time-history analysis the nonlinear behavior of materials can be pictured and the response can be found out as a function of time during the seismic event [11].

Numerical integration in structural dynamics is dominated by "single step-single solve" algorithms, where the response is updated one step at a time by solving only one system of equations of the size of the similar static equations. The response of an inelastic MDOF system at time $i$ is given with

$$
m \ddot{u}_{i}+c \dot{u}_{i}+\left(f_{s}\right)_{i}=\left(m I \ddot{u}_{g}\right)_{i}
$$

Time-stepping methods enable the determination of the response of the sys- 
tem at time $i+1$ :

$$
m \ddot{u}_{i+1}+c \dot{u}_{i+1}+\left(f_{s}\right)_{i+1}=\left(m I \ddot{u}_{g}\right)_{i+1}
$$

Newmark developed a series of time-stepping methods based on the following Equation [7]

$$
\begin{gathered}
\dot{u}_{i+t}=\dot{u}_{i}+[(1-\gamma) \Delta t] \ddot{u}_{i}+(\gamma \Delta t) \ddot{u}_{i+t} \\
u_{i+t}=u_{i}+(\Delta t) \dot{u}_{i}+\left[(0.5-\beta)(\Delta t)^{2}\right] \ddot{u}_{i}+\left[\beta(\Delta t)^{2}\right] \ddot{u}_{i+t}
\end{gathered}
$$

where, the parameters $\gamma$ and $\beta$ define the variation of acceleration over a time step which determines the stability and accuracy characteristics of the method. Typical values used are $\gamma=1 / 2$ and $1 / 6 \leq \beta \leq 1 / 4$. In this thesis the average acceleration algorithm is used which is the Newmark method are $\gamma=1 / 2$ and $\beta=$ $1 / 4$.

\subsection{Damping Theory}

Every structure available till now show some degree of energy loss during motion. This energy loss is referred to three main sources in numerical analysis which are due to nonlinearity of members, energy radiation and inherent structural damping. The characteristics of damping forces in vibrating structures have long been under utmost interest of Engineers. Damping capacity is defined as the ratio of the energy dissipated in one full cycle of oscillation to the maximum amount of energy added up in the structure [12].

\section{Rayleigh Proportional Damping}

In nonlinear analysis cases such as in Time History analysis, the equation of motion of any structure should be solved directly. To solve the equation of motion the mass, stiffness and stiffness matrices should be known. By using the assumptions of the linear viscous damping in structures which focuses on Rayleigh damping, the damping matrix can be showed as a function of stiffness matrices and mass matrices. The model expresses damping is a linear combination or merging of the mass matrices and stiffness matrices altogether [13]. Damping used in direct integration time history analysis is described with the damping matrix, $c$ which is shown by

$$
c=a_{0} m+a_{1} k
$$

This is called Rayleigh damping. The damping ratio for the $n^{\text {th }}$ mode of such a system is

$$
\xi_{n}=\frac{a_{0}}{2 \omega_{n}}+\frac{a_{1}}{2} \omega_{n}
$$

The coefficients $a_{0}$ and $a_{1}$ are determined from damping ratios $\zeta_{i}$ and $\zeta_{j}$ for mode $i$ and $j$ respectively. It is reasonable to have the same damping ratio for modes $i$ and $j$. The coefficients are given by 


$$
\begin{aligned}
& a_{0}=\xi \frac{2 \omega_{i} \omega_{j}}{\omega_{i}+\omega_{j}} \\
& a_{1}=\xi \frac{2}{\omega_{i}+\omega_{j}}
\end{aligned}
$$

We calculated $a_{0}=0.027, a_{1}=0.090$, as Rayleigh damping and used it in the time-history analysis for solid pier bridge, and $a_{0}=0.025, a_{1}=0.096$ for hollow pier bridge. The Rayleigh damping represent the damping of the bridge without the lead rubber bearings. The energy dissipation of the isolation devices is automatically included in the calculations through their nonlinear definition.

\section{General Features of the Bridge}

The bridge analyzed is a pre-stressed concrete rigid frame mountainous railway bridge. Bridge is 496 meters long having 7 spans. It is a two-lane pre-stressed concrete girder bridge. The highest pier is of 81 meters. The design speed of the bridge adopted is $250 \mathrm{~km} / \mathrm{h}$. It is designed for lying of double-deck block ballast less track. The line spacing of two-lane Bridge is 4.8 meters and deck clear width is $12.20 \mathrm{~m}$. There are 8 numbers of piers. The bridge is symmetric in the bearing availability of girders in respective piers. In this paper, the piers are recognized according to the numbers given from left to right i.e. 1 to 8 . \#1 and \#8 are simply supported, $\# 4$ and \#5 are fixed bearings, \#2, \#3, \#6 and \#7 are actively supported bearings.

\subsection{Pier Type Selection}

Two types of piers are analyzed along with the bridge-Solid Pier and Thin Walled Hollow Pier. The different piers are analyzed such that they have same sectional areas. So, when they have same sectional areas it is obvious they should have different inertial dimensions. It does not make a huge difference of the impact of seismic waves on a bridge whether we chose to adopt the cross-sectional area or the bending moment of inertia of the piers the same. Whether resistance to the magnitude of the earthquake or not, is not only decided by the pier cross-section and bending moment of inertia $I_{X}$ and $I_{Y}$, but also to a greater extent by structure itself and its vibration characteristics [14]. For the comparative analysis, we adopted solid piers and hollow piers section area basically differ by around $40 \%$ but its $I_{x}, I_{y}$ and Torsional coefficient are used the same. The different piers with their respective heights are given in Table 1.

\subsection{Foundation and Geology}

The pile foundation was modeled as Winkler's Model. By the help of the model, we tried to find the number of rows of the base stiffness of flexible pile foundation.

Table 1. Pier heights.

\begin{tabular}{ccccccccc}
\hline Pier & $\# 1$ & $\# 2$ & $\# 3$ & $\# 4$ & $\# 5$ & $\# 6$ & $\# 7$ & $\# 8$ \\
\hline Height $(\mathrm{m})$ & 65 & 80 & 81 & 80 & 79 & 77 & 71 & 65 \\
\hline
\end{tabular}


In this paper, we consider only one layer of soil for simplicity. Because it is a comparative analysis, it may not have very adverse effect on the results. The type of soil adopted is soft plastic clay having liquidity index $I_{L}>1.0$ and silty clay having $1.0 \geq I_{L}>0.75$.

\subsection{Applied Load}

\subsubsection{Dead Load}

The dead load of girder is calculated by multiplying the cross-sectional area with concrete density $\left(2450 \mathrm{~kg} / \mathrm{m}^{3}\right)$ and its length. All structural elements are made of concrete and the self-weight is calculated from the density and its total volume. The dead load from girder is not shown here. Self-weight of main structural elements per meter and total weight is shown in Table 2.

\subsubsection{Earthquake Loads}

\section{1) The Design Response Spectrum}

The design response spectrum is evaluated and used from the peak ground acceleration given by Eurocode 8 part 1 [15] as shown in Table 3. It is taken on the topmost $30 \mathrm{~m}$ of soil thickness from ground level.

These values serve as input to the calculations on the shape of the horizontal design response spectrum which is defined by the following expressions

$$
\begin{aligned}
& 0 \leq T \leq T_{B}: S_{d}(T)=a_{g} \cdot S \cdot\left(2 / 3+T / T_{B} \cdot(2.5 / q-2 / 3)\right) \\
& T_{B} \leq T \leq T_{C}: S_{d}(T)=a_{g} \cdot S \cdot(2.5 / q) \\
& T_{C} \leq T \leq T_{D}: S_{v e}(T)=a_{g} \cdot S \cdot(2.5 / q)\left(T_{C} / T\right) \geq \beta \cdot a_{g} \\
& T_{D} \leq T: S_{d}(T)=a_{g} \cdot S \cdot(2.5 / q)\left(T_{C} \cdot T_{D} / T^{2}\right) \geq \beta \cdot a_{v g}
\end{aligned}
$$

Table 2. Dead load.

\begin{tabular}{cccccc}
\hline Item & Width $(\mathrm{m})$ & Thickness $(\mathrm{m})$ & Mass $(\mathrm{kg})$ & Number & Total mass $(\mathrm{kg})$ \\
\hline Sleeper & 0.654 & 0.26 & 2450 & 4 & 1666 \\
Road bed board & 2.8 & 0.18 & 2450 & 2 & 2470 \\
Protective layer & 1.2 & 0.12 & 2400 & 1 & 346 \\
4 rails & - & - & 60 & 4 & 240 \\
Others & - & - & - & - & 500 \\
Total & & & & & $\mathbf{5 2 2 2}$ \\
\hline
\end{tabular}

${ }^{\star}$ Calculated per meter.

Table 3. Details of calculation for the design response spectrum.

\begin{tabular}{cc}
\hline Ground Type & $\mathrm{D}$ \\
\hline Importance factor, $\gamma_{\mathrm{I}}$ & 1 \\
Shear wave velocity, $v_{s, 30}$ & 150 \\
Peak ground acceleration, $a_{g}$ & $0.3 \mathrm{~g}$ \\
Behavior factor, $q$ & 1.2 \\
\hline
\end{tabular}


where,

$S_{d}(T)$-Design response spectrum;

$S$-Soil factor;

$T_{B}$-Lower limit of the period of the constant spectral acceleration branch;

$T_{C}$-Upper limit of the period of the constant spectral acceleration branch;

$T_{D}$-Value defining the beginning of constant displacement response ranges of the spectrum;

$a_{g}-$ Design ground acceleration on type $\mathrm{D}$ ground;

$q$-Behavior factor;

$\beta$-Lower bound factor for the horizontal design spectrum.

The values of these variables basically depend on the ground type and expected surface-wave magnitude. The values for Type 1 horizontal design response spectrum, ground type $\mathrm{D}$, are listed in Table 4 .

Due to the need to verify the three different forms of reactions to the post-earthquake input, so input ground motion from the $\mathrm{x}$-direction is only considered. For modal combination, complete quadratic combination (CQC) method has been adopted in this paper.

\section{2) Dynamic Time History}

In this paper, in order to facilitate comparison of different forms of the forces and displacements of the bridges, the uniform application of earthquake input acceleration time history is performed. For the analysis, longitudinal ground motion is the only input, without considering other orthogonal directions of ground motion as in response spectrum method. The results were analyzed without considering the impact of the acceleration due to gravity. In order to perform seismic response of structure models, three earthquake acceleration records were selected and utilized in time-history analysis. In order to observe the effect of earthquake, these records were scaled linearly to the 0.3 PGA.

The details of different earthquakes used in this thesis are given in Table 5.

\subsection{FE Model of the Bridge}

In this research, the methodology used is to conduct study, create models and carry out a series of simulation analyses using a simple model using FEM. A procedure is generated to obtain the effect of relative displacement and internal

Table 4. Parameters for type 1 design horizontal response spectrum.

\begin{tabular}{ccccc}
\hline Ground Type & $S$ & $T_{B}$ & $T_{C}$ & $T_{D}$ \\
\hline D & 1.35 & 0.2 & 0.8 & 2 \\
\hline
\end{tabular}

Table 5. Earthquake loads.

\begin{tabular}{ccccc}
\hline Earthquake & Country & Year & Moment Magnitude & Unscaled PGA \\
\hline El Centro-NS & USA & 1940 & 6.9 & 0.349 \\
Wenchuan-EW & China & 2008 & 8.0 & 0.97 \\
Nepal & Nepal & 2015 & 7.8 & 0.42 \\
\hline
\end{tabular}


forces on the behavior of the bridges with different types of piers. The bridge is modeled in finite element model (FEM) by ANSYS 15.0 software. The finite element method approximates a structure as a cluster of elements or components with various forms of connection between them and each element of which has its own specific stiffness and definite properties. A FE modeling can be an extremely powerful tool to compute the dynamic response of the system without running expensive experimental testing [16].

\section{ANSYS Element Selection}

In this paper, bridge parts (girder, pier and pile cap) is defined by using BEAM4 ("ANSYS 15") element. The material properties, their units and their values that are adopted in this thesis for BEAM4 elements are as follows.

$E X$-Young's modulus of elasticity, $\mathrm{N} / \mathrm{m}^{2}$ [3.45E +10$]$;

DENS-Mass density, $\mathrm{kg} / \mathrm{m}^{3}$ [2650];

$G X Y$-Poisson's ratio [0.2].

The girder mass is defined by MASS21 ("ANSYS 15") element. The constants used for MASS21 element:

- $\operatorname{MASS}(X, Y$ and Z-directions));

- INERTIA

The pile foundation of the bridge is modeled by using COMBIN14 ("ANSYS 15 ”) spring-damper element. Whereas, the pile cap is modeled by using BEAM4 element as mentioned earlier. KEYOPT (2) $=1$ to 6 is used for defining the element as a one-dimensional element. With these options, the element operates in the nodal coordinate system. To assign these elements, separate 6 nodes for each pile foundation system are allocated which coincides with each other. The six different elements so formed are provided with each different constants.

The general outlook of the two bridge types using FEM are given in Figure 1 and Figure 2.

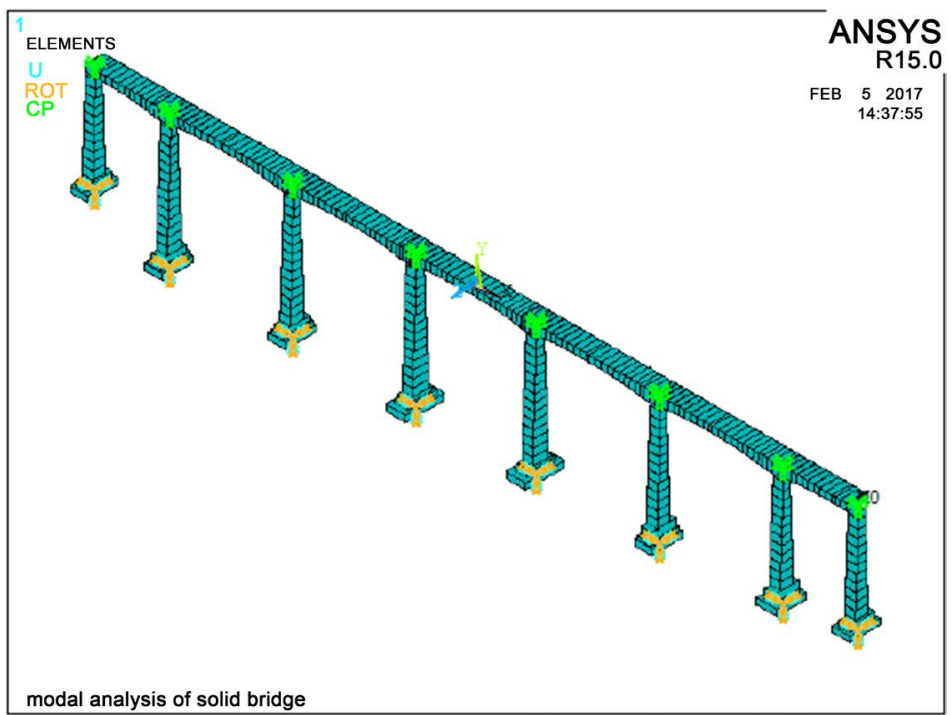

Figure 1. FEM of solid pier bridge. 


\section{The Results}

\subsection{Results from Modal Analysis}

The fundamental frequency with respect to the mode numbers of two bridges are given in Table 6 along with their mode descriptions. The modification in the fundamental natural period due to the change in pier type is studied in Figure 3. The percentage variation in natural period of solid pier as compared to hollow pier bridge was found to be $6.3 \%$.

\section{Modal List and Vibration Pattern}

According to the theoretical knowledge about the natural vibration characteristics of the bridge by dynamic analysis, the bridge takes the first 300 vibration mode. The vibration characteristics were calculated using the subspace iteration

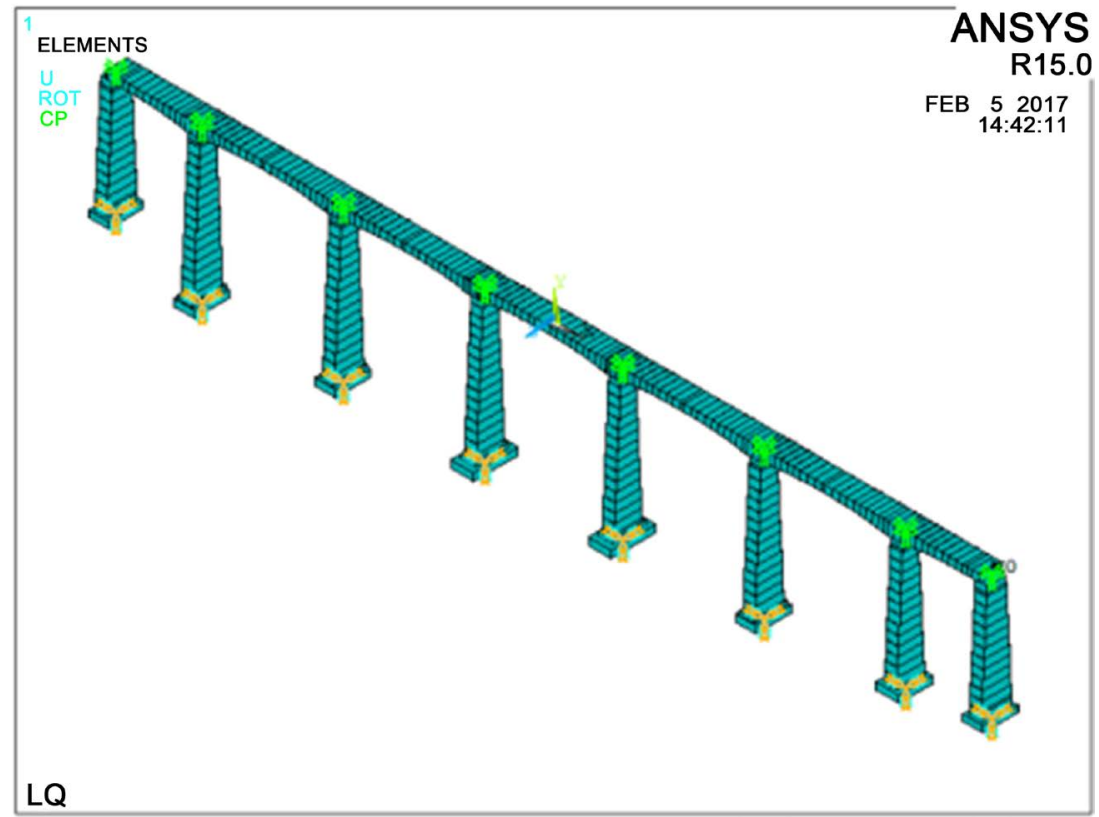

Figure 2. FEM of hollow pier bridge.

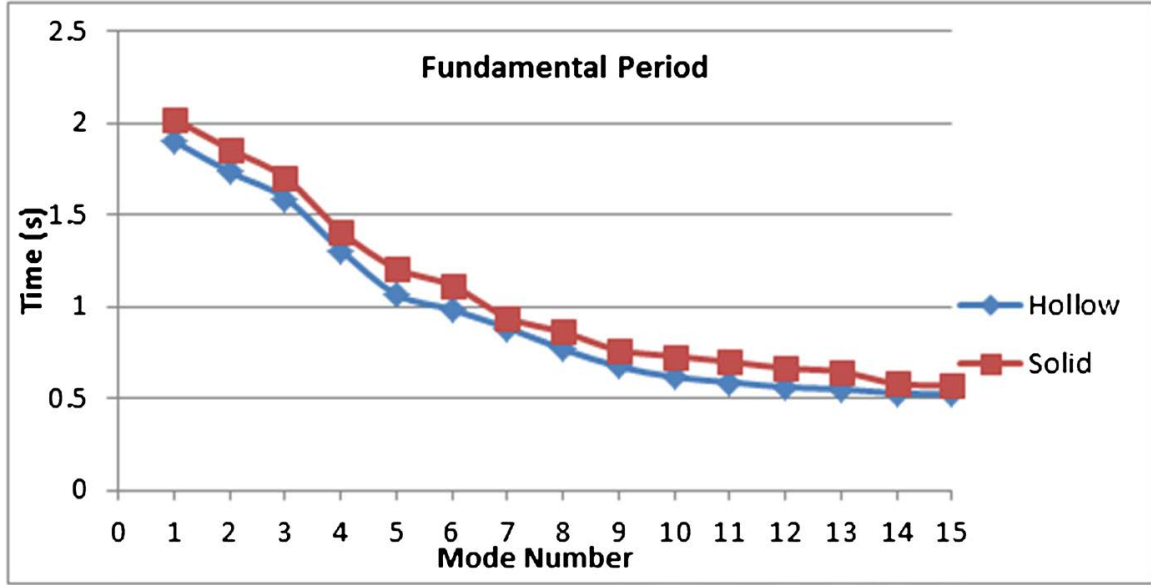

Figure 3. Fundamental natural period of solid and hollow pier bridges. 
method. The first 15 vibration mode order and its frequency and vibration pattern of first mode of both bridges are given in Table 6 .

\subsection{Results from Response Spectrum Analysis}

\section{Analysis of the Results}

\section{Analysis of internal forces and displacements on bridges}

From the lower part of the two-bridge structures represented by Figures 4-7, we can see some of its internal forces' general situation. The outward bending moment of solid pier bridge is $17 \%$ to $40 \%$ higher than the hollow pier bridge. The axial force of solid pier bridge is $21 \%$ to $30 \%$ more than the hollow pier bridge. Similarly, maximum values are at piers $1,4,5$ and 8 . The longitudinal shear force of first and last solid piers has around 53\% and $65 \%$ more value than solid pier respectively. Whereas, remaining solid piers have more values than hollow piers by around $12 \%$ to $50 \%$. The maximum values of longitudinal shear force lies on the central piers i.e. $4^{\text {th }}$ and $5^{\text {th }}$ piers.

Table 6. Mode number and frequency table of hollow and solid pier bridges.

\begin{tabular}{|c|c|c|c|c|}
\hline \multirow{2}{*}{$\begin{array}{l}\text { Mode } \\
\text { Number }\end{array}$} & \multicolumn{2}{|r|}{ Hollow Pier Bridge } & \multicolumn{2}{|r|}{ Solid Pier Bridge } \\
\hline & Frequency & Description & Frequency & Description \\
\hline 1 & 0.525 & $\begin{array}{l}\text { The main beam bending, and its corresponding pier } \\
\text { transverse bending }\end{array}$ & 0.494 & $\begin{array}{l}\text { The main beam transverse bending, and its } \\
\text { corresponding pier transverse bending }\end{array}$ \\
\hline 2 & 0.576 & $\begin{array}{l}\text { The main beam is laterally symmetrically curved, and the } \\
\text { piers are bent laterally }\end{array}$ & 0.538 & $\begin{array}{l}\text { The main beam is laterally symmetrically curved, } \\
\text { and the piers are bent laterally }\end{array}$ \\
\hline 3 & 0.628 & $\begin{array}{l}\text { Lateral bending of \#2, \#3, \#6 and \#7 piers and its } \\
\text { corresponding girder }\end{array}$ & 0.587 & $\begin{array}{l}\text { The main beam is laterally symmetrically curved, } \\
\text { and the piers are bent laterally }\end{array}$ \\
\hline 4 & 0.764 & $\begin{array}{l}\text { The main beam transverse anti-symmetrical bending, the } \\
\text { pier transverse bending }\end{array}$ & 0.708 & $\begin{array}{l}\text { The main beam transverse anti-symmetrical } \\
\text { bending, the pier transverse bending }\end{array}$ \\
\hline 5 & 0.936 & The main beam transverse symmetrical bending & 0.827 & The main beam is symmetrically curved \\
\hline 6 & 1.014 & $\# 1, \# 8$ piers transverse anti-symmetric bending & 0.895 & $\begin{array}{l}\# 1, \# 4, \# 5, \# 8 \text { piers bent laterally and its } \\
\text { corresponding transverse anti-symmetric bending } \\
\text { of girder }\end{array}$ \\
\hline 7 & 1.129 & $\# 1, \# 4, \# 5$ and \#8 piers longitudinal displacement & 1.063 & $\# 1, \# 4, \# 5$ and $\# 8$ piers longitudinal displacement \\
\hline 8 & 1.3 & $\begin{array}{l}\text { The main beam transverse symmetrical bending, the pier } \\
\text { transverse bending }\end{array}$ & 1.159 & $\begin{array}{l}\text { The main beam is laterally symmetrically curved, } \\
\text { and the piers are bent laterally }\end{array}$ \\
\hline 9 & 1.482 & $\begin{array}{l}\text { The main beam is laterally anti-symmetrically bent, and } \\
\text { the piers are bent laterally }\end{array}$ & 1.309 & $\begin{array}{l}\text { The main beam transverse anti-symmetrical } \\
\text { bending, the pier transverse bending }\end{array}$ \\
\hline 10 & 1.62 & \#2 pier longitudinal bending & 1.367 & \#2 pier longitudinal bending \\
\hline 11 & 1.696 & \#3 pier longitudinal bending & 1.427 & \#3 pier longitudinal bending \\
\hline 12 & 1.779 & \#6 pier longitudinal bending & 1.501 & \#6 pier longitudinal bending \\
\hline 13 & 1.813 & \#7 pier longitudinal bending & 1.546 & \#7 pier longitudinal bending \\
\hline 14 & 1.886 & $\begin{array}{l}\# 1, \# 2, \# 3 \text { piers and its corresponding girder vertical } \\
\text { bending }\end{array}$ & 1.722 & $\begin{array}{l}\# 1, \# 2, \# 3 \text { piers and its corresponding girder vertical } \\
\text { bending }\end{array}$ \\
\hline 15 & 1.911 & $\begin{array}{l}\# 6, \# 7, \# 8 \text { piers and its corresponding girder vertical } \\
\text { bending }\end{array}$ & 1.748 & $\begin{array}{l}\# 6, \# 7, \# 8 \text { piers and its corresponding girder vertical } \\
\text { bending }\end{array}$ \\
\hline
\end{tabular}




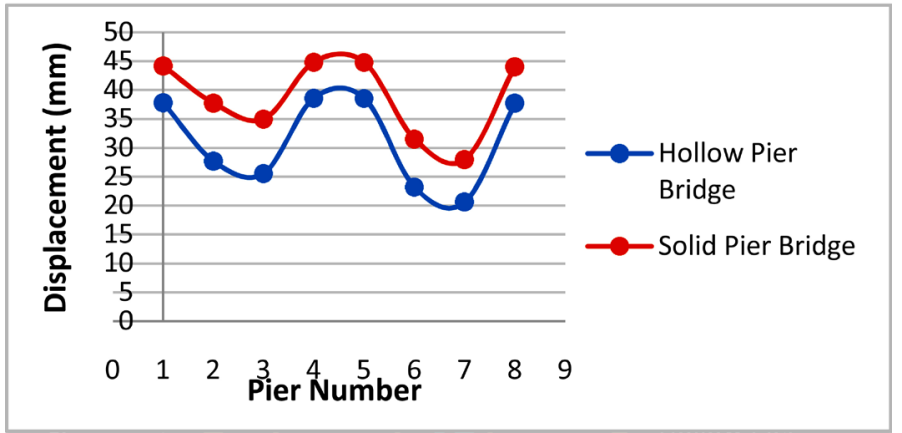

Figure 4. Response spectrum displacement results.

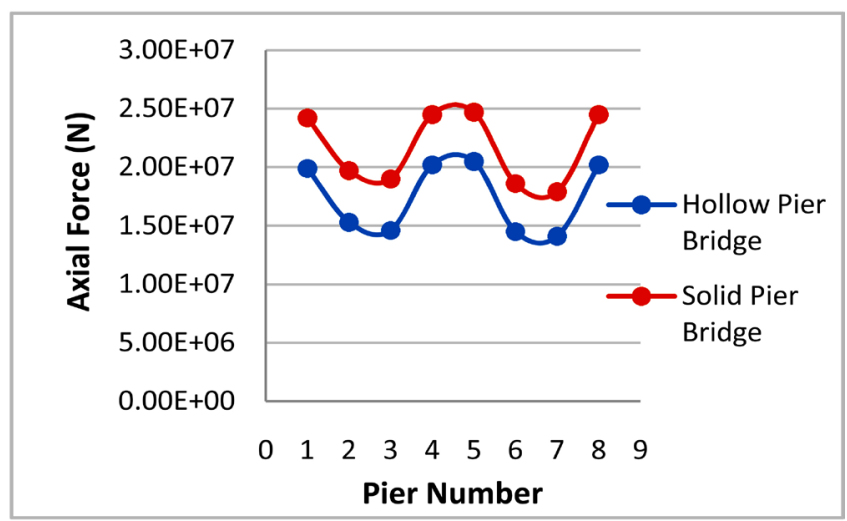

Figure 5. Response spectrum axial force results.

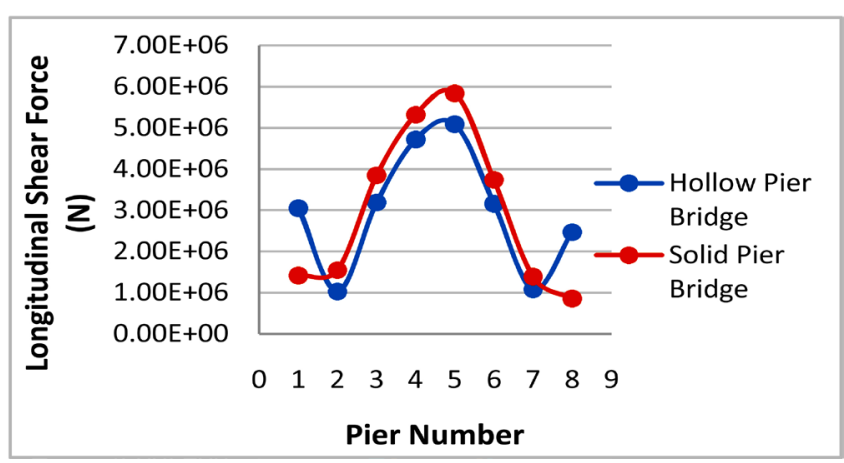

Figure 6. Response spectrum base shear results.

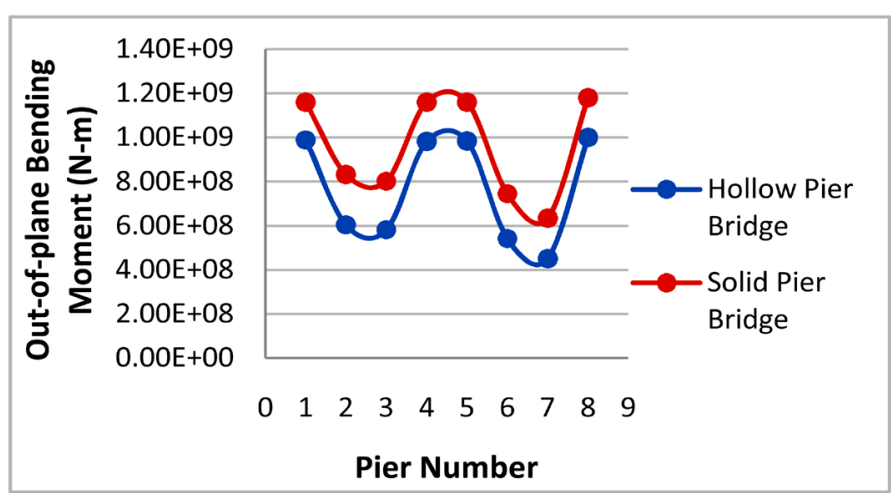

Figure 7. Response spectrum moment results. 
The hollow pier uses its own flexibility to consume the seismic force. The use of the hollow high pier, due to its flexibility generates displacement to dissipate damaging effects on the structure by seismic energy. From the response spectra calculations, we can say hollow piers have a greater advantage than solid piers. For the two types of pier bridges, solid piers have relatively more longitudinal displacement than hollow piers. The maximum displacements can be found on first, last and middle piers numbered 1, 4, 5 and 8 . The displacement of the main girder is also found to be more relative to other central piers. For hollow pier bridge, the displacement of girder is $37.69 \mathrm{~mm}$ whereas $44.02 \mathrm{~mm}$ for girder of solid pier bridge.

\subsection{Results from Dynamic Time-History Analysis}

For continuous girder bridge, the most unfavorable cross-section generally appear at the pier end, the maximum displacement generally appear in the main beam and the top of each pier.

\section{Analysis of the Results from Time-History Analysis}

The time-history analysis results obtained from the earthquake waves of three different earthquakes are given in Figures 8-19. The results from the three earthquakes are almost similar in trend but they are different in values of course. If we want to compare the results between different earthquakes, Nepal earthquake

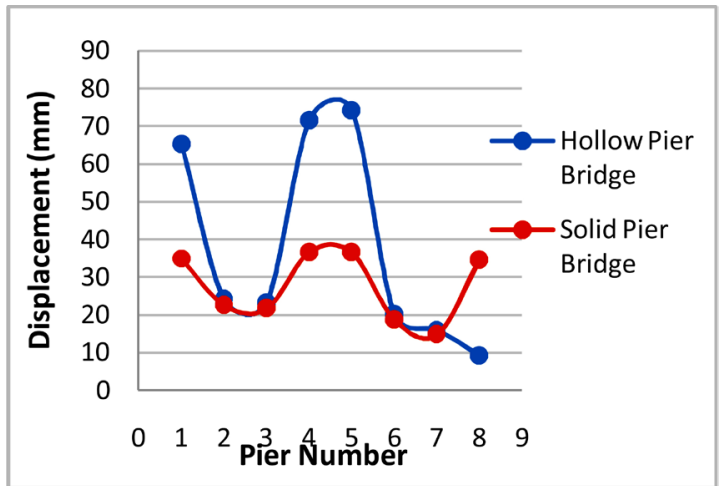

Figure 8. Longitudinal displacement results.

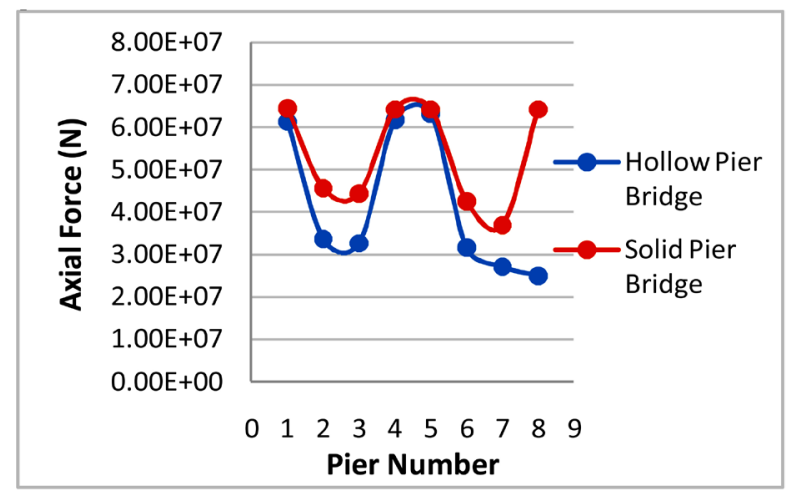

Figure 9. Axial force results. 


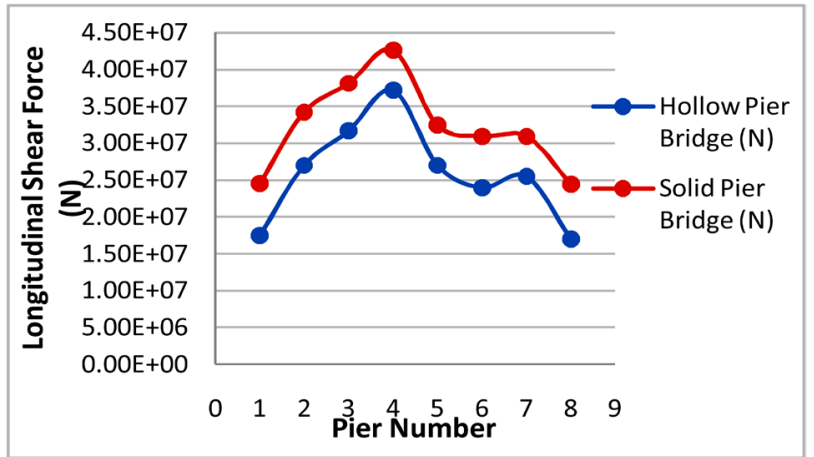

Figure 10. Base shear results.

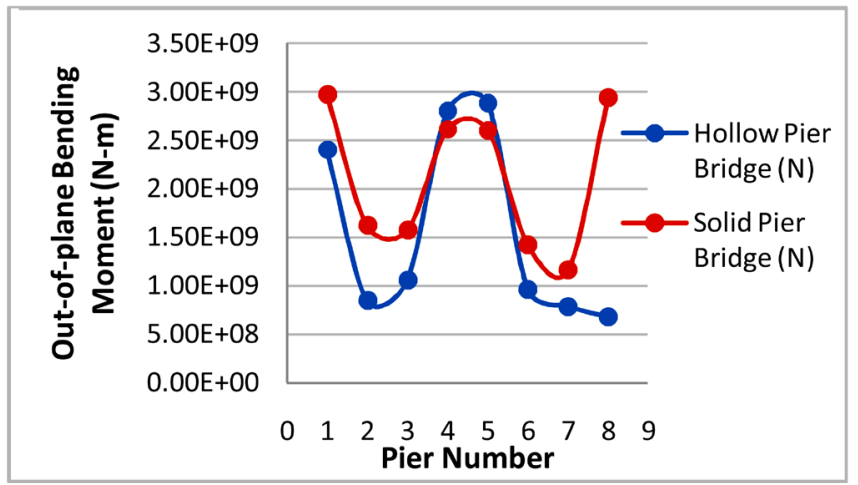

Figure 11. Bending moment results.

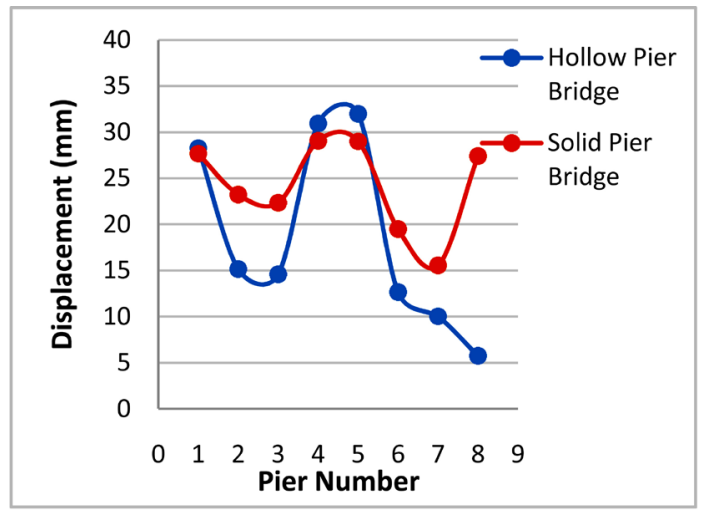

Figure 12. Longitudinal displacement results.

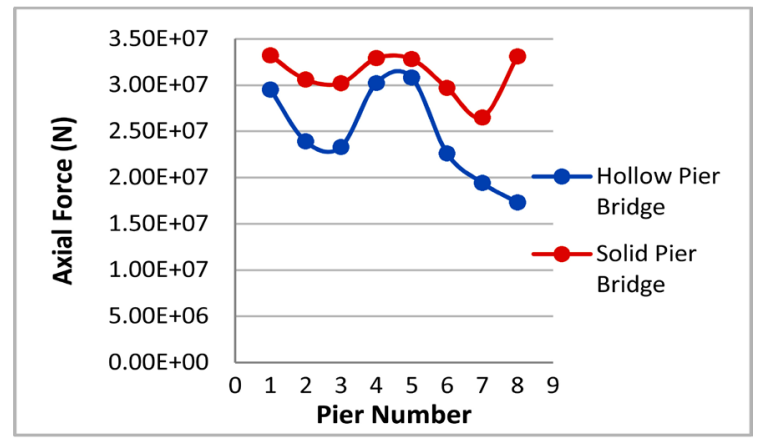

Figure 13. Axial force results. 


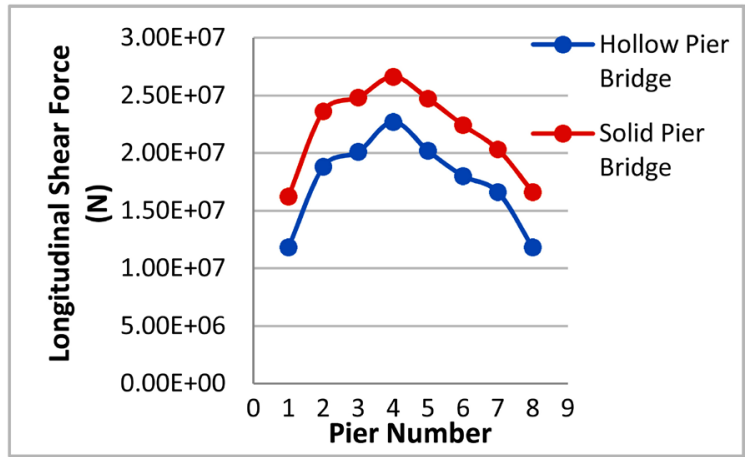

Figure 14. Base shear results.

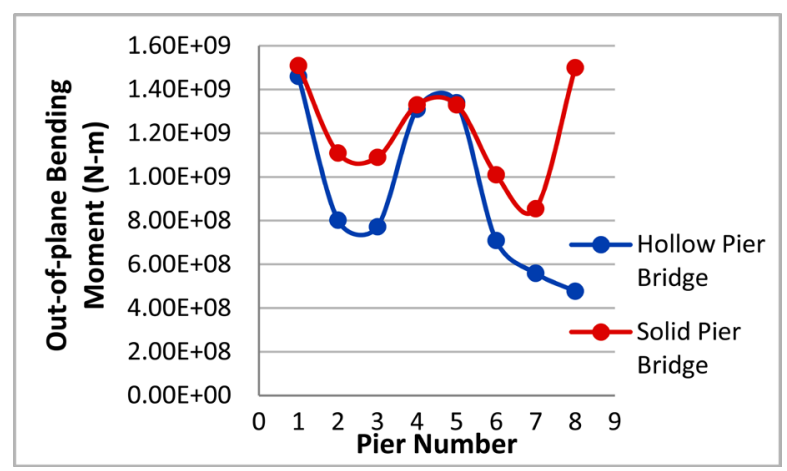

Figure 15. Bending moment results.

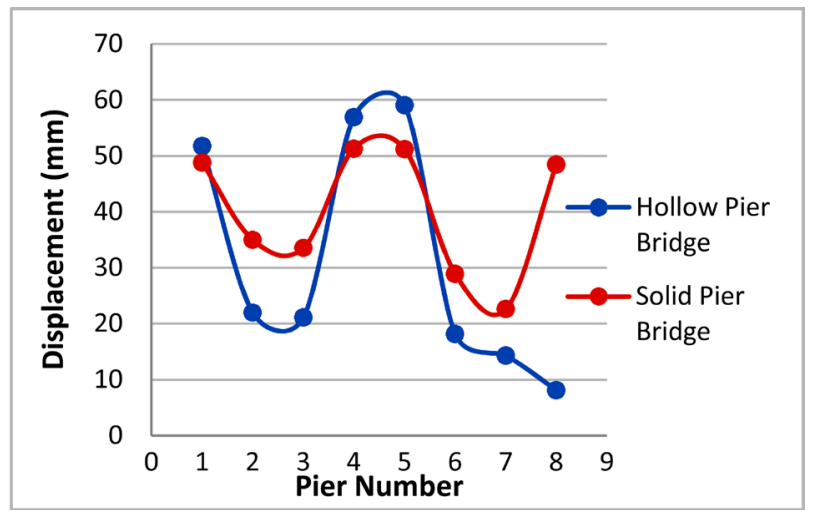

Figure 16. Longitudinal displacement results.

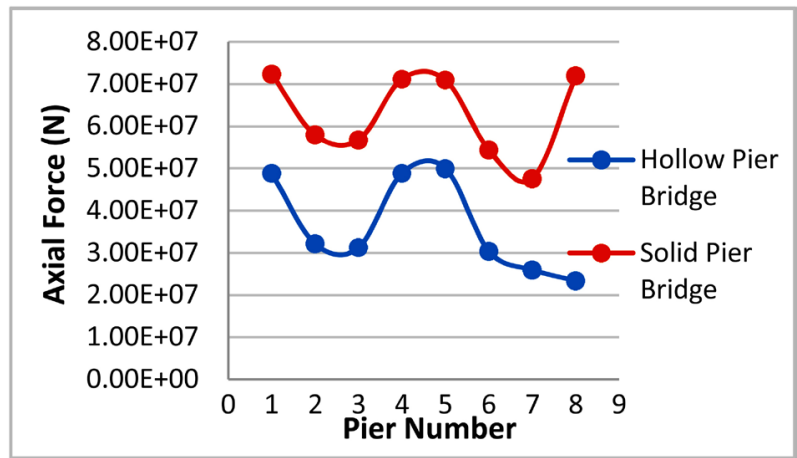

Figure 17. Axial force results. 


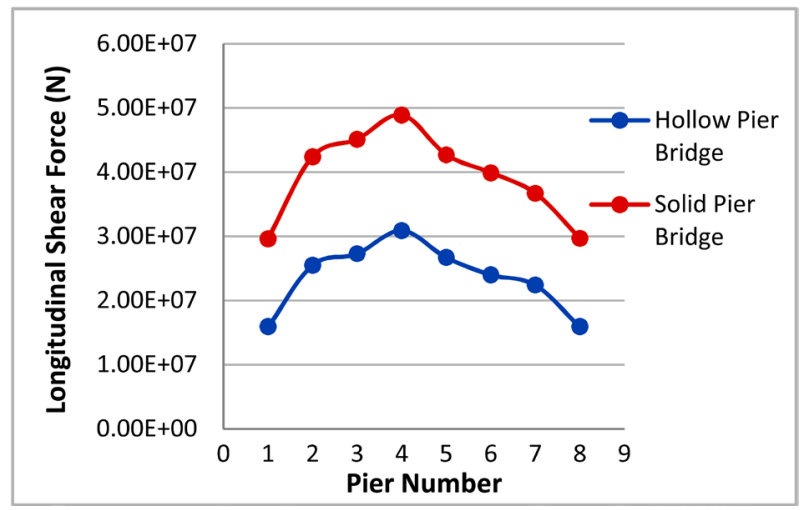

Figure 18. Base Shear results.

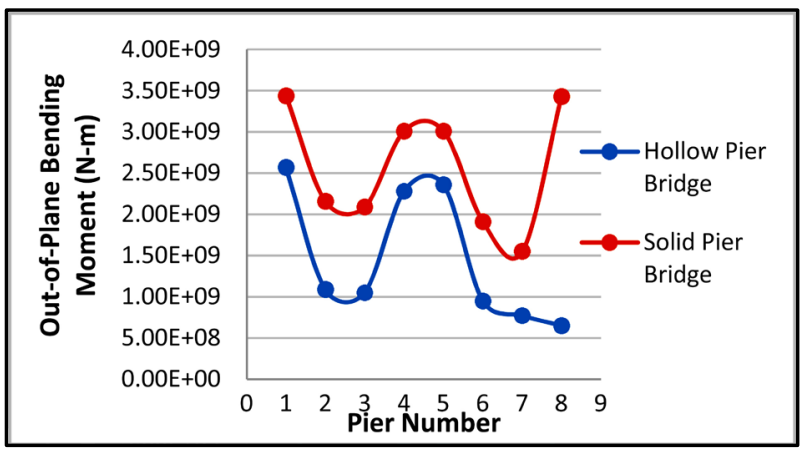

Figure 19. Bending Moment results.

generates the maximum value which is then followed by Elcentro earthquake and then by Wenchuan earthquakes. The results can be comparable because they all are normalized to the scale of $0.3 \mathrm{~g}$ as already mentioned in previous sections.

\section{Analysis of results from internal forces and displacements}

Maximum values of axial force lies on pier numbers 1, 4, 5 and 8 for solid pier bridge and same is the condition for hollow pier bridge except for pier number 8 for different earthquakes. The results of longitudinal shear force notifies that the bridges don't have high irregular values in all the earthquakes cases. Solid pier bridge has more values than hollow pier bridges for each and every piers by about $17 \%$ to $41 \%$. Maximum values of out-of plane bending moment lies on pier numbers 1, 4, 5 and 8 for solid pier bridge and same is the condition for hollow pier bridge except for pier number 8 for Elcentro and Nepal earthquakes. For Wenchuan earthquake, solid pier system doesn't have much difference in values between different piers but it certainly has differences for hollow pier system. From the figures it can be seen that, the resulting forces and moments of the solid pier is bigger than the result obtained from hollow pier, which reflects the results discussed in the previous spectrum were consistent if we compare its trend with time-history analysis results.

If we want to compare longitudinal displacements of the two types of piers of bridges due to earthquake loads, hollow piers have relatively more longitudinal displacement than solid piers for piers $1^{\text {st }}, 4^{\text {th }}$ and $5^{\text {th }}$. But for other piers, 
solid piers have more displacement for all the earthquake waves used. The maximum displacements can be found on first, last and middle piers numbered 1, 4 and 5 for hollow piers and pier number 8 for solid pier. The displacement of the main girder is also found to be more relative to other central piers. We got those results because hollow pier itself is a flexible input to resist earthquake forces, so its displacement with respect to the solid pier is larger for some piers but the pier and main beam forces and moments have decreased significantly which shows better seismic performance. The solid pier uses its own rigidity to resist input earthquake forces; the displacement shift is small but has a lot of internal forces and moments which upgrades seismic performance in general.

\subsection{Comparison between Earthquakes with Different PGA Values}

In this section, we want to know the trend of the results for different PGA values. For this, different PGA values i.e. $0.1 \mathrm{~g}, 0.15 \mathrm{~g}, 0.2 \mathrm{~g}, 0.25 \mathrm{~g}$ and $0.3 \mathrm{~g}$ were used. Values of only one element of the hollow pier bridge and results from axial force were considered for simplicity purpose.

The PGA is a measure of maximum amplitude of motion and is defined as the largest absolute value of acceleration time-history. From Figure 20, it can be seen that the curves are uniformly linear. If we want to compare the results from different earthquakes for the same PGA value, Nepal earthquake induces the maximum axial force between these three.

\section{Conclusions}

In this research, we checked the seismic performances of mountainous high-pier continuous rigid frame bridges having different pier types. The analyses were done by using numerical finite element method using software called ANSYS

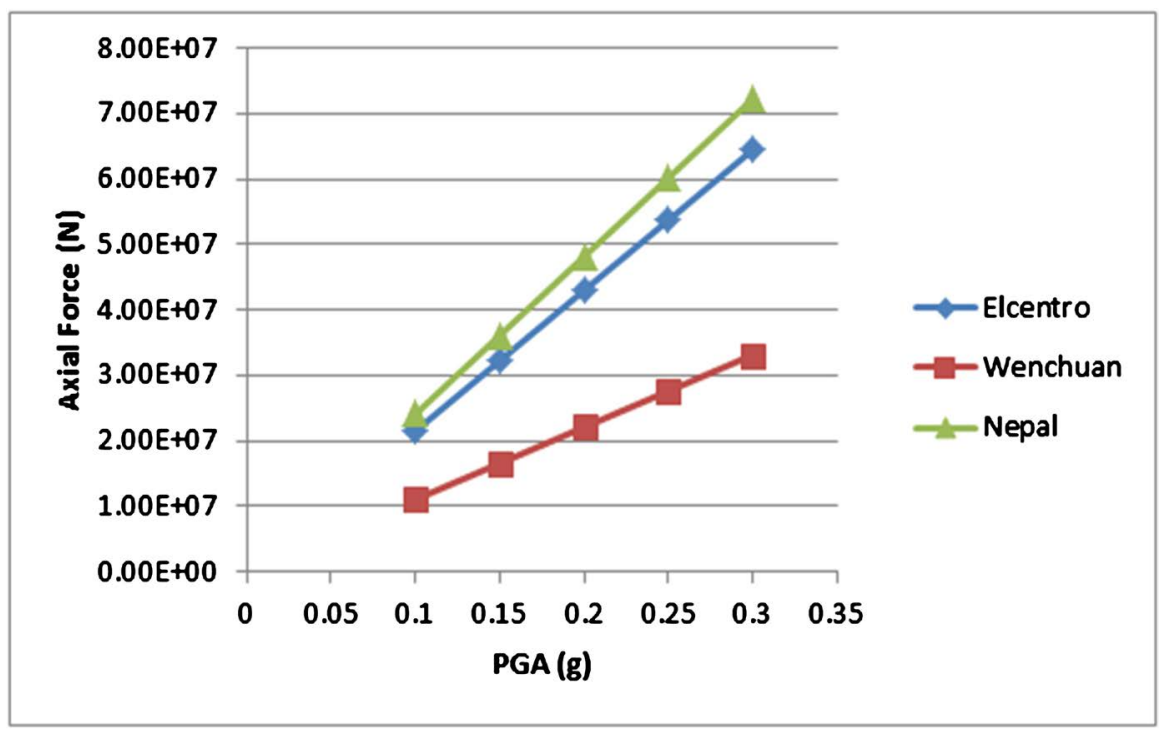

Figure 20. Trend of the effects of different earthquakes using different PGA values. 
15.0. The analyses of the bridges were done by Response Spectrum Analysis as well as Time-history Analysis methods using three different earthquake waves i.e. Elcentro, Wenchuan and Nepal earthquakes all having PGA of $0.3 \mathrm{~g}$. According to the results obtained from all those analyses, we can conclude that:

1) In the high pier continuous rigid frame bridge, by using hollow piers it is obvious that the material will be saved in considerable amount and should be more flexible comparatively. However, due to its large displacement in certain piers it is necessary to increase the area of upper structure in order to prevent from falling of beams. It should be ensured that even if the upper structure is detached from the seat of the pier, the beam may not fall directly for safety measures.

2) Due to its good integrity of the high solid pier bridge because its longitudinal displacement is smaller in certain piers, only small accidents are more likely to occur than hollow pier bridges. But due to its huge internal forces in big earthquakes, brittle failure is likely to occur. Therefore, in the design and construction of a solid pier, additional reinforcement and stirrups should be given to improve key parts of bending and shear properties.

3) For high intensity mountainous high pier concrete continuous rigid frame bridge, the adoption of hollow pier bridge has advantages like-material saving, seismic performance and many other advantages.

\section{Acknowledgements}

The financial support from The Project of Science and Technology Department in Sichuan Province under Grant Number 2015HH0058, is greatly appreciated. I am grateful to my supervisor professor Li Xiaozhen for his guidance, ideas and encouragement during the work.

\section{Conflicts of Interest}

The authors declare no conflicts of interest regarding the publication of this paper.

\section{References}

[1] Kim, C.W., Kawatani, M. and Konaka, S. (2011) Seismic Responses of a Highway Viaduct Considering Vehicles of Design Live Load as Dynamic System during Moderate Earthquakes. Structure and Infrastructure Engineering, 7, 523-534. https://doi.org/10.1080/15732479.2010.493339

[2] Zheng, Q.X. and Liu, W.H. (2010) Seismic Design of High Piers for Mountain Bridges. ARPN Journal of Engineering and Applied Sciences, 5, 58-63.

[3] Mo, Y.L. and Nien, I.C. (2002) Seismic Performance of Hollow High-Strength Concrete Bridge Columns. Journal of Bridge Engineering, 7, 338-349. https://doi.org/10.1061/(ASCE)1084-0702(2002)7:6(338)

[4] Pinto, A., Pegon, P., Magonette, G., Molina, J. and Buchet, G. (2002) Pseudo-Dynamic Tests on a Large-Scale Model of an Existing RC Bridge Using Non-Linear Substructuring and Asynchronous Motion. European Commission 
Joint Research Centre, ELSA Laboratory.

[5] Ou, Y.-C., Chiewanichakorn, M., Aref, A.J. and Lee, G.C. (2007) Seismic Performance of Segmental Precast Unbonded Posttensioned Concrete Bridge Columns. Journal of Structural Engineering, 133, 1636-1647. https://doi.org/10.1061/(ASCE)0733-9445(2007)133:11(1636)

[6] Heinkelé, C., Pernot, S., Sgard, F. and Lamarque, C.-H. (2006) Vibration of an Oscillator with Random Damping: Analytical Expression for The probability Density Function. Journal of Sound and Vibration, 296, 383-400. https://doi.org/10.1016/j.jsv.2006.03.003

[7] Chopra, A. (2007) Dynamics of Structures. 2nd Edition, Prentice Hall, Upper Saddle River.

[8] Ayman, A.S. (2011) Site Specific Probabilistic Seismic Hazard Analysis at Dubai Creek on the West Coast of UAE. Parsons Corp. Broadway, New York, NY.

[9] Takewaki, F.K. and Nakamura, I.N. (2008) Critical Disturbance for Stress Resultant in Long-Span Moment Resisting Frames Subjected to Horizontal and Vertical Simultaneous Ground Inputs. Journal of Structural and Construction Engineering (Transactions AI)), 187.

[10] Wilson, E.B.E.L. and Der Kiereghian, A. (1981) A Replacement for the SRSS Method in Seismic Analysis. Vol. 9, University of California, Berkeley, 187.

[11] El-Maaddawy, T., Nessabi, A. and El-Dieb, A. (2013) Flexural Response of Corroded Reinforced Concrete Beams Strengthened with Powder-Actuated Fastened Composites. Journal of Composites for Construction, 17. https://doi.org/10.1061/(ASCE)CC.1943-5614.0000395

[12] Adhikari, S. and Woodhouse, J. (2001) Identification of Damping: Part 1, Viscous Damping. Journal of Sound and Vibration, 243, $43-61$.

https://doi.org/10.1006/jsvi.2000.3391

[13] Casarotti, C. and Pinho, R. (2006) Seismic Response of Continuous Span Bridges through Fiber-Based Finite Element Analysis. Structure and Mechanical Department, University of Pavia, Pavia

[14] Wilson, E.L. (2002) Three-Dimensional Static and Dynamic Analysis of Structures. 3rd Edition, Computers and Structures, Computers and Structures, 234-249.

[15] (2005) Eurocode 8: Design of Structures for Earthquake Resistance-Part 2: Bridges. Authority European Union per Regulation 305/2011, Directive 98/34/EC, Directive 2004/18/EC, Vol. EN 1998-2.

[16] Desai, C.S. and Abel, J.F. (1987) Introduction to the Finite Element Method: A Numerical Method for Engineering Analysis. CBS Publishers and Distributors, Delhi. 